\title{
A Longitudinal Growth Mixture Model of Child Disclosure to Parents Across Adolescence
}

\author{
Laura M. Padilla-Walker \\ Brigham Young University - Provo \\ Daye Son \\ Brigham Young University - Provo \\ Larry J. Nelson \\ Brigham Young University - Provo, larry_nelson@byu.edu
}

Follow this and additional works at: https://scholarsarchive.byu.edu/facpub

Part of the Other Social and Behavioral Sciences Commons

\section{Original Publication Citation}

Padilla-Walker, L. M., Son, D., \& Nelson, L. J. (2018). A longitudinal growth mixture model of child disclosure to parents across adolescence. Journal of Family Psychology, 32, 475-483.

\section{BYU ScholarsArchive Citation}

Padilla-Walker, Laura M.; Son, Daye; and Nelson, Larry J., "A Longitudinal Growth Mixture Model of Child Disclosure to Parents Across Adolescence" (2017). Faculty Publications. 4704.

https://scholarsarchive.byu.edu/facpub/4704 


\title{
A Longitudinal Growth Mixture Model of Child Disclosure to Parents Across Adolescence
}

\author{
Laura M. Padilla-Walker, Daye Son, and Larry J. Nelson \\ Brigham Young University
}

\begin{abstract}
The present study used a person-centered approach to examine heterogeneity in children's patterns of routine disclosure (i.e., sharing information regarding their whereabouts and activities to parents) across adolescence and explored predictors and outcomes of different trajectories. Participants included 500 adolescents (51\% female, 67\% White, 33\% single-parent families) who completed questionnaires every year from age 12 to age 18 . Growth mixture modeling suggested that the majority of adolescents $(82 \%)$ experienced a gradual decrease in disclosure to parents across adolescence, while another group (13\%) reported low and stable disclosure, and a third group (5\%) a steep decrease and leveling out over time. Group membership varied as a function of predictors at age 12 (delinquency, prosocial behavior, maternal warmth) and of outcomes at age 18 (delinquency, substance use, depression, prosocial behavior). The discussion focuses on the implications of this person-centered approach for adolescent disclosure to parents across adolescence.
\end{abstract}

Keywords: child disclosure, adolescence, longitudinal

One of the most consistent protective factors against problem behavior during adolescence is positive parenting, including parental involvement and awareness of what their teenager is doing. Indeed, parental knowledge of their child has been linked to a number of adaptive outcomes during childhood and adolescence (Stattin \& Kerr, 2000; Willoughby \& Hamza, 2011). Since child disclosure, or a child's willingness to share information about their activities, whereabouts, and companions (Racz \& McMahon, 2011), has been identified as the strongest predictor of parental knowledge (Crouter \& Head, 2002), recent research has examined adolescent information management (disclosure, secrecy) and its interactions with various aspects of the parent-child relationship (e.g., Tilton-Weaver, 2014) and child behavioral outcomes such as delinquency (e.g., Laird \& Marrero, 2010). Despite the crosssectional and longitudinal work that has been done, most of it has been from a variable-centered perspective and has not taken heterogeneity into account. In other words, there is still more to be known about how variation in trajectories of child routine disclosure across adolescence may be tied longitudinally to later outcomes. Hence, the purpose of the current study was twofold: to (a)

This article was published Online First December 28, 2017.

Laura M. Padilla-Walker, Daye Son, and Larry J. Nelson, School of Family Life, Brigham Young University.

We recognize the generous support of the many private donors who provided support for this project. We thank the Family Studies Center at Brigham Young University, the School of Family Life, and the College of Family Home and Social Science at Brigham Young University, and we also thank those families who were willing to spend valuable hours with our team in interviews, and the many students who assisted in conducting the interviews.

Correspondence concerning this article should be addressed to Laura M. Padilla-Walker, School of Family Life, Brigham Young University, 2071 JFSB, Provo, UT 84602. E-mail: laura_walker@byu.edu longitudinally examine patterns of child disclosure across adolescence, and (b) to explore both predictors and outcomes of these trajectories.

\section{Patterns of Child Disclosure Across Adolescence}

A growing body of longitudinal research has revealed relatively consistent patterns of child disclosure over time. For example, one study found that disclosure decreased and concealment increased across early adolescence (Laird, Marrero, Melching, \& Kuhn, 2013), and another found that disclosure decreased gradually from age 13 to 16 (Keijsers, Frijns, Branje, \& Meeus, 2009). A longerterm longitudinal study (ages 12-19) found that early adolescents showed a decline in their willingness to disclose to their parents, but then in later adolescence girls tended to again become more open in their communication (e.g., more disclosure and less secrecy) while boys' levels of secrecy remained stable (Keijsers \& Poulin, 2013). Taken together, these studies suggest that in general, child disclosure to parents declines across adolescence, but may rebound toward late adolescence. While this longitudinal pattern is somewhat logical and perhaps expected as autonomy increases, it does not capture potential variability over time in trajectories of disclosure. Given that multiple aspects of the parent-child relationship (Racz \& McMahon, 2011) and the child's own behavior (e.g., delinquency; Kerr, Stattin, \& Burk, 2010) are associated with child disclosure and vary widely across individual adolescents, it is also likely that child disclosure varies at any given time during adolescence, as well as across time. Variable-centered approaches assume that a sample is drawn from a single population, homogeneous in regard to the parameters of interest (Laursen \& Hoff, 2006), while person-centered approaches identify groups of individuals who are similar or who share a set of characteristics. For example, adolescents who have a weak relationship with parents and high levels of delinquency during early adolescence may have different trajectories of disclosure 
over time than adolescents who have a strong relationship with parents and low levels of delinquency. Given the ways in which person-centered analyses can complement variable-centered analyses in adding to our understanding of developmental processes, the first goal of the current study was to explore heterogeneity in longitudinal trajectories of routine child disclosure over time.

\section{Predictors of Child Disclosure}

A number of predictors have been linked to child disclosure in adolescence. In terms of child-driven factors, delinquency has been found to be associated longitudinally with less child disclosure (Keijsers, Branje, VanderValk, \& Meeus, 2010) and more concealment (Laird et al., 2013) during adolescence (Salari \& Thorell, 2015). Delinquent adolescents are often involved in activities that parents do not approve of, so children may actively limit the amount of information given to parents in order to avoid negative parental reactions (Marshall, Tilton-Weaver, \& Bosdet, 2005). Child gender has also been related to child disclosure, with girls reporting more disclosure than boys (Keijsers, Branje, Frijns, Finkenauer, \& Meeus, 2010), as reported by both parents and adolescents (Stattin \& Kerr, 2000). Girls compared to boys may share more information with parents because they are less likely to be delinquent and thus less likely to withhold information (Kerr \& Stattin, 2000) or because parents grant greater autonomy to girls than boys (especially first-born girls, Bumpus, Crouter, \& McHale, 2001), which might promote more open disclosure.

In terms of parent-driven predictors, various positive parenting factors including parental acceptance (Garthe, Sullivan, \& Kliewer, 2015), understanding, and warmth (Tilton-Weaver et al., 2010) have been found to be longitudinally associated with child disclosure. Having a quality relationship with parents may foster greater child disclosure because a warm, open family environment helps adolescents to feel comfortable sharing information with their parents (Soenens, Vansteenkiste, Luyckx, \& Goossens, 2006). Family structure has also been found to be associated with child disclosure in that adolescents from singleparent families report less child disclosure than do adolescents from two-parent families (Padilla-Walker, Harper, \& Bean, 2011). It is possible that due to structural constraints, singleparent families lack resources that foster parent-child communication (McLanahan, Tach, \& Schneider, 2013) such as parental engagement (Carlson \& Berger, 2013). Given existing research on predictors of child disclosure, the second purpose of our study was to predict patterns of child disclosure based on child's delinquency, gender, family structure, and parent-child relationship quality (maternal warmth and prosocial behavior toward family).

\section{Outcomes of Child Disclosure}

Child disclosure has been linked to a number of positive child outcomes across adolescence. First and foremost, child disclosure is the strongest predictor of parental knowledge, both crosssectionally and longitudinally (Laird \& Zeringue, in press; Soenens et al., 2006), even when considering the child's own level of delinquent behavior (Racz \& McMahon, 2011). Studies have also found that child disclosure in adolescence is associated either directly or indirectly with lower levels of externalizing behaviors like delinquency (Keijsers et al., 2009; Keijsers, Branje, VanderValk et al., 2010), substance use (Soenens et al., 2006), and deviant peer association. It is also linked with lower levels of internalizing problems such as depressive symptoms (Laird et al., 2013) and low self-esteem (Tilton-Weaver et al., 2010). Furthermore, adolescent disclosure has positive effects on parent-child relationships (Smetana, Villalobos, Tasopoulos-Chan, Gettman, \& Campione-Barr, 2009) and maternal warmth (Cumsille, Darling, \& Martínez, 2010).

Taken together, child disclosure has consistently been linked to the absence of negative outcomes, while less often being linked to the promotion of positive outcomes beyond improvement in the parent-child relationship (Racz \& McMahon, 2011). In addition, few studies have explored whether child disclosure during the formative years is associated with child outcomes during the transition to adulthood. This may be important because despite the increased desire for independence after children graduate high school, research suggests that parents continue to be an important influence in the lives of their children (Nelson, Padilla-Walker, Christensen, Evans, \& Carroll, 2011). Thus, as part of the second purpose of this study, we examined how patterns of disclosure across adolescence predicted adjustment (e.g., prosocial behavior toward family, maternal warmth) and maladjustment (e.g., externalizing problems, depression) in late adolescence.

\section{Current Study}

The current study sought to add to the literature on child disclosure by taking a person-centered approach to longitudinal trajectories of child disclosure. While research suggests that generally levels of disclosure decrease across adolescence (e.g., Keijsers \& Poulin, 2013), the current study explored whether there was variability in trajectories across time. Given the exploratory nature of this research question, we did not have specific hypotheses in this regard. In addition to exploring heterogeneity over time, the current study sought to understand how child characteristics and behaviors (e.g., gender, delinquency) and aspects of the family or parent-child relationship (e.g., family structure, maternal warmth, prosocial behavior toward family) at age 12 might be associated with different trajectories over time, and whether different trajectories of child disclosure might be differentially associated with both positive (maternal warmth, prosocial behavior toward family) and negative (delinquency, substance use, depression) behavioral outcomes during late adolescence. Based on past research (Padilla-Walker et al., 2011; Salari \& Thorell, 2015; Tilton-Weaver et al., 2010) we expected that being female, being from a two-parent home, and having a higher quality relationship with parents and lower levels of delinquency at age 12 would be associated with moderate to high levels of disclosure across adolescence. Also, given research on the protective role of child disclosure (e.g., Keijsers et al., 2009; Keijsers, Branje, VanderValk et al., 2010), we expected that adolescents with moderate to high levels of child disclosure across adolescence would have more positive outcomes overall at age 18 than adolescents who might have low levels of disclosure; but again, specific hypotheses were difficult given the exploratory nature of these research questions. 


\section{Method}

\section{Participants and Procedure}

At Wave 1 of the current study participants consisted of 500 adolescents $(51 \%$ female, $M$ age $=11.57,33 \%$ single-parent families) from the Flourishing Families Project (FFP). Adolescents and their parents participated every year, starting in 2007, and longitudinal retention was over $90 \%$. Regarding ethnicity, $67 \%$ of participants were European American, 11\% were African American, and $22 \%$ were multiethnic or other ethnicities. Eighteen percent of families reported an income less than $\$ 40,000$ per year, $48 \%$ made between $\$ 40,000$ and $\$ 100,000$ a year, and $34 \%$ made more than $\$ 100,000$ per year. Because each wave of data had an age range of up to 4 years, the data were restructured according to age so the current study focused on adolescents when they were age 12 and then every year until they were age 18 (resulting in 7 time points, each 1 year apart). Missing data before restructuring were minimal $(<5 \%)$, but were handled using the Maximum Likelihood feature in Mplus (Muthén \& Muthén, 2010).

After receiving approval from the institutional review board at Brigham Young University (Protocol F060311, The FFP), at Wave 1 families were randomly selected from targeted census tracts that mirrored the socioeconomic and racial stratification of reports of local school districts, and were contacted directly using a multistage recruitment protocol. All families with a child between the ages of 10 and 14 living within target census tracts were deemed eligible to participate in the study. Of the 692 eligible families contacted, 423 agreed to participate, resulting in a $61 \%$ response rate at Time 1 . In an attempt to more closely mirror the demographics of the local area, a limited number of families were recruited into the study through other means (e.g., referral, fliers; $n=77,15 \%$ ), resulting in 500 total families participating at Wave 1. Researchers visited the family's home and administered questionnaires to adolescents at the first five waves, and questionnaires were administered online in later waves.

\section{Measures}

Child disclosure. Adolescents reported on five items regarding their own routine disclosure to parents using a measure slightly adapted from Kerr and Stattin (2000). Responses ranged from 1 (never) to 5 (always) with higher scores indicating greater child disclosure ( $\alpha=.75-.92$; e.g., "I tell my parent about what I do with my free time." "I tell my parents how I spend my money"). Adolescents responded to these questions every year from age 12 to age 18 .

Delinquency. Adolescents reported on their own delinquent behavior ( 9 items, $\alpha=.75, .76$; e.g., "I lie or cheat" and "I steal things from places other than home.") at age 12 and 18 (Barber, Stolz, \& Olsen, 2005). Responses ranged from 0 (not true) to 2 (often true), with higher scores representing higher levels of delinquent behavior.

Prosocial behavior toward family. Adolescents' prosocial behavior toward family was assessed at age 12 and 18 using a modified version of the Kindness and Generosity subscale of the Values in Action Inventory of Strengths (Peterson \& Seligman, 2004). The original measure was designed to assess behaviors toward strangers, and the current study used nine of these original items to assess prosocial behavior toward family members ( 9 items, $\alpha=.92, .91$; e.g., "I really enjoy doing small favors for my family") on a 5-point Likert scale ranging from 1 (not like me at all) to 5 (very much like me). Higher scores were indicative of more prosocial behavior toward family.

Maternal warmth. Adolescents reported on their mother's warmth and support at age 12 and 18 using the warmth/support subscale of the Parenting Styles and Dimensions QuestionnaireShort Version (PSDQ, Robinson, Mandleco, Olsen, \& Hart, 2001). Adolescents were asked how often mothers did certain behaviors indicative of warmth, such as, "My mother is responsive to my feelings and needs." Responses ranged on a 5-point Likert-type scale from 1 (never) to 5 (always), with higher scores indicating higher levels maternal warmth $(\alpha=.92, .90)$.

Substance use. Adolescents responded to six items at age 18 drawn from the Adolescent Alcohol and Drug Involvement Scale (AADIS, Moberg \& Hahn, 1991). Responses ranged from 1 (never used) to 7 (several times a day) and higher scores indicated higher frequency of substance use. Questions referred to smoking, drinking, marijuana, other illegal drugs, prescription medication, and binge drinking $(\alpha=.81)$.

Depression. Adolescents reported on their own depression (13 items, $\alpha=.75$; e.g., "I am unhappy, sad or depressed" and "I feel worthless or inferior"; Barber et al., 2005) at age 18. Responses ranged from 0 (not true) to 2 (often true), with higher scores representing higher levels of depressive symptomology.

\section{Results}

\section{Descriptive Statistics and Correlations}

Descriptive statistics and correlations for all continuous study variables are shown in Table 1 . It is of note that delinquency, prosocial behavior toward family, and maternal warmth at age 12 were associated with child disclosure in the expected direction at almost every age. In addition, delinquency, substance use, prosocial behavior, and maternal warmth at age 18 were associated with child disclosure in the expected direct at almost every age. Depression at age 18 was less consistently and strongly associated with child disclosure.

\section{Growth Curve Analysis}

Using Mplus software (Muthén \& Muthén, 2010), first we conducted a growth curve analysis of child disclosure from ages $12-18$. The growth curve had good model fit $\left(\chi^{2}(19)=51.86, p<\right.$ $.001, \mathrm{CFI}=.98, \mathrm{RMSEA}=.06, \mathrm{SRMR}=.03)$ and suggested that the intercept $(\mathrm{I}=4.01, p<.001)$, slope $(\mathrm{S}=-.25, p<.001)$, and quadratic $(\mathrm{Q}=.03, p<.001)$ were all statistically significant (see Figure 1). In addition, there was significant variance around the intercept $(\mathrm{I}=.48, p<.001)$, slope $(\mathrm{S}=.10, p<.001)$, and quadratic $(\mathrm{Q}=.002, p<.001)$, suggesting that a mixture model may reveal meaningful heterogeneity in the trajectories of child disclosure over time.

\section{Growth Mixture Model of Child Disclosure}

We next we conducted a growth mixture model (GMM) of child disclosure across 7 years. To determine the number of classes, we 
Table 1

Descriptive Statistics and Correlations of All Continuous Study Variables

\begin{tabular}{|c|c|c|c|c|c|c|c|c|c|c|c|c|c|c|c|}
\hline Variable & 1 & 2 & 3 & 4 & 5 & 6 & 7 & 8 & 9 & 10 & 11 & 12 & 13 & 14 & 15 \\
\hline 1. Child disclosure 12 & - & & & & & & & & & & & & & & \\
\hline 2. Child disclosure 13 & $.60^{* * * * *}$ & - & & & & & & & & & & & & & \\
\hline 3. Child disclosure 14 & $.53^{* * * *}$ & $.63^{* * * *}$ & - & & & & & & & & & & & & \\
\hline 4. Child disclosure 15 & $.45^{* * * *}$ & $.56^{* * *}$ & $.63^{* * * *}$ & - & & & & & & & & & & & \\
\hline 5. Child disclosure 16 & $.34^{* * * * *}$ & $.43^{* * * *}$ & $.54^{* * * *}$ & $.67^{* * * * *}$ & - & & & & & & & & & & \\
\hline 6. Child disclosure 17 & $.31^{* * * *}$ & $.40^{* * * * *}$ & $.45^{* * * *}$ & $.55^{* * * *}$ & $.63^{* * * *}$ & - & & & & & & & & & \\
\hline 7. Child disclosure 18 & $.26^{* * * *}$ & $.34^{* * * *}$ & $.38^{* * * * *}$ & $.42^{* * * *}$ & $.46^{* * * *}$ & $.58^{* * * *}$ & - & & & & & & & & \\
\hline 8. Delinquency 12 & $-.39^{* * * *}$ & $-.32^{* * * *}$ & $-.20^{* * * *}$ & $-.26^{* * * *}$ & $-.13^{* * *}$ & $-.16^{* *}$ & $-.17^{* *}$ & - & & & & & & & \\
\hline 9. Prosocial behavior 12 & $.43^{* * * *}$ & $.32^{* * * * *}$ & $.33^{* * * *}$ & $.27^{* * * *}$ & $.19^{* * *}$ & $.21^{* * * * *}$ & .11 & $-.26^{* * * *}$ & - & & & & & & \\
\hline 10. Maternal warmth 12 & $.60^{* * * *}$ & $.43^{* * * *}$ & $.37^{* * * *}$ & $.38^{* * * *}$ & $.24^{* * *}$ & $.22^{* * * *}$ & $.19^{* *}$ & $-.24^{* * * *}$ & $.49^{* * * *}$ & - & & & & & \\
\hline 11. Delinquency 18 & $-.19^{* * * * *}$ & $-.26^{* * * *}$ & $-.24^{* * * *}$ & $-.29^{* * * *}$ & $-.29^{* * * *}$ & $-.19^{* * * *}$ & $-.24^{* * * *}$ & $.30^{* * * * *}$ & .05 & -.07 & - & & & & \\
\hline 12. Substance use 18 & $-.13^{*}$ & $-.22^{* * * *}$ & $-.26^{* * * *}$ & $-.27^{* * * * *}$ & $-.31^{* * * *}$ & $-.22^{* * * *}$ & $-.23^{* * * *}$ & $.24^{* * * *}$ & -.07 & -.10 & $.68^{* * * * *}$ & - & & & \\
\hline 13. Depression 18 & $-.10^{*}$ & $-.11^{*}$ & $-.11^{*}$ & -.08 & $-.15^{* *}$ & $-.12^{*}$ & $-.16^{* * *}$ & $.13^{*}$ & -.05 & $-.13^{*}$ & $.19^{* * * *}$ & $.15^{* *}$ & - & & \\
\hline 14. Prosocial behavior 18 & $.25^{* * * *}$ & $.16^{* * * *}$ & $.25^{* * * *}$ & $.29^{* * * *}$ & $.30^{* * * *}$ & $.34^{* * * *}$ & $.34^{* * * *}$ & $-.11^{*}$ & $.40^{* * * * *}$ & $.25^{* * * *}$ & $-.15^{* *}$ & -.09 & $-.14^{* *}$ & - & \\
\hline 15. Maternal warmth 18 & $.21^{* * * * *}$ & $.23^{* * * *}$ & $.29^{* * * * *}$ & $.30^{* * * * *}$ & $.37^{* * * *}$ & $.41^{* * * * *}$ & $.51^{* * * *}$ & $-.15^{* *}$ & $.25^{* * * * *}$ & $.33^{* * * * *}$ & -.07 & -.10 & $-.22^{* * *}$ & $.38^{* * * * * *}$ & - \\
\hline$M$ & 4.02 & 3.83 & 3.57 & 3.51 & 3.50 & 3.50 & 3.51 & .12 & 4.02 & 4.03 & .37 & 1.77 & 1.78 & 4.11 & 3.81 \\
\hline$S D$ & .81 & .83 & .84 & .84 & .84 & .80 & .78 & .18 & .77 & .79 & .30 & 1.03 & .60 & .76 & .86 \\
\hline
\end{tabular}

Note. Number after variables is age of adolescent.

${ }^{*} p<.05 .{ }^{* * *} p<.01 .{ }^{* * * *} p<.001$.

examined the Bayesian Information Criterion (BIC) and the sample size adjusted BIC (SABIC). The BIC favors models with few parameters and smaller sample sizes (Tofighi \& Enders, 2008). The SABIC adds an adjustment to reduce the sample size penalty. Given the BIC and SABIC may indicate differing numbers of classes, we also employed the Lo-Mendell-Rubin Likelihood Ratio test (LMR), examined class sizes, and took entropy (a measure of how well cases are classified) into account. BIC and SABIC indicate better model fit with lower values, while entropy with values approaching 1 indicates clear delineation of classes (Celeux \& Soromenho, 1996).

There was clear improvement in model fit when moving from one to two classes and the SABIC and LMR test suggested improved model fit when moving from two to three classes but reduced model fit when moving from three to four classes (see

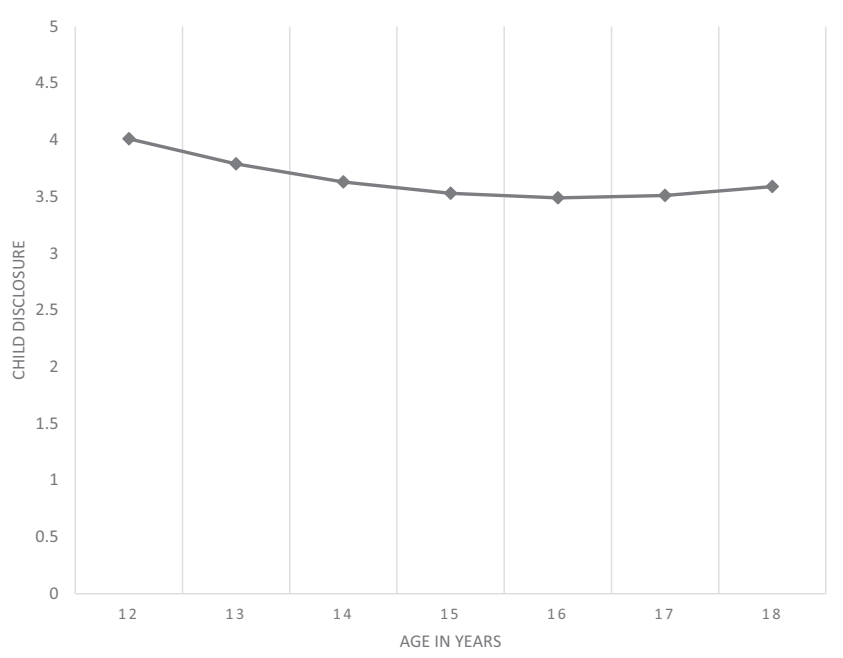

Figure 1. Growth curve of child disclosure. $\chi^{2}(19)=51.86, p<.001$, CFI $=.98$, RMSEA $=.06$, SRMR $=.03$. Intercept $=4.01, p<.001$, Slope $=-.25, p<.001$, Quadratic $=.03, p<.001$.
Table 2). Thus, we selected the three-class solution. Figure 2 displays the growth trajectories of the classes, with Table 3 containing growth parameters. Class $1(82 \%, n=411)$ was similar to the growth curve above with a relatively high intercept in early adolescence, a gradual but steady decrease until age 16 and then a slight increase from age 16 to age 18 . We refer to Class 1 as "Gradual Decrease." Class $2(13 \%, n=66)$ had a low intercept and a nonsignificant slope and quadratic, so we refer to Class 2 as "Low-Stable." Class $3(5 \%, n=23)$ had the highest intercept during early adolescence, but then had a rather sharp decline until age 16 and then a relatively steep increase from age 16 to age 18 . We refer to Class 3 as "Sharp Decrease-Increase." It is of note that all three groups reported similar levels of child disclosure by age 18 .

\section{Predictors and Outcomes of Trajectories of Child Disclosure}

Once the GMM was established, the r3step approach in Mplus was used with class membership regressed on the predictors of class membership (gender, family structure, delinquency, prosocial behavior, maternal warmth - all at age 12). The base category was switched across regressions so that all pairwise comparisons were made (see Table 4). Class 2 (low-stable) had higher levels of delinquency and lower levels of prosocial behavior toward family and maternal warmth at the initial time point than did Class 1 (gradual decrease). There were few significant differences at the initial time point between Class 3 (sharp decrease-increase) and either of the other classes, though Class 3 did have marginally higher levels of maternal warmth at age 12 compared to Class 2 . Trajectories did not vary as a function of child gender.

Next, the du3step approach in Mplus was used to examine if class means differed on outcome variables assessed at age 18 (delinquency, substance use, depression, pro social behavior, and parental warmth). Table 5 contains tests of mean differences across outcome variables as a function of class membership. It is of note that Class 1 (gradual decrease) had lower levels of delinquency 
Table 2

Relative Model Fit by Number of Latent Classes

\begin{tabular}{clccccc}
\hline Classes & Class size $(n)$ & Log-likelihood & Entropy & AIC & BIC & SABIC \\
\hline 1 & 500 & -3224.42 & - & 6480.83 & 6548.27 & 6497.48 \\
2 & 438,62 & -3204.49 & .74 & 6448.98 & 6533.27 & 6469.79 \\
$\mathbf{3}$ & $\mathbf{4 1 1 , 6 6 , 2 3}$ & $\mathbf{- 3 1 9 3 . 2 5}$ & $\mathbf{. 7 5}$ & $\mathbf{6 4 3 4 . 5 1}$ & $\mathbf{6 5 3 5 . 6 7}$ & $\mathbf{6 4 5 9 . 4 8}$ \\
4 & $24,40,76,360$ & -3189.68 & .67 & 6435.36 & 6553.37 & 6464.50 \\
\hline
\end{tabular}

Note. $\quad$ AIC $=$ Akaike information criterion; $\mathrm{BIC}=$ Bayesian Information Criterion; SABIC $=$ sample size adjusted BIC; LMR $=$ Lo-Mendell-Rubin Likelihood Ratio test. AIC, BIC, and SABIC values in bold represent the best fitting class.

and substance use, and higher levels of prosocial behavior than did Class 2 (low-stable) and 3 (sharp decrease-increase). None of the outcomes assessed distinguished between Class 2 and 3. It is also of note that there were no significant differences in maternal warmth at age 18 as a function of class.

\section{Discussion}

A growing body of research has explored longitudinal change in child disclosure to parents, and has found that there is generally a gradual decline in adolescent disclosure across adolescence with a rebound into late adolescence (Keijsers et al., 2009; Keijsers \& Poulin, 2013; Laird et al., 2013). However, variable-centered approaches do not take heterogeneity into account, and have been unable to identify different trajectories in child disclosure that might be meaningful. Thus, the twofold purpose of this study was to (a) longitudinally examine patterns of child disclosure across adolescence, and to (b) explore predictors and outcomes of these different trajectories. Results revealed three different classes of adolescents who were distinct in their patterns of change in levels of routine disclosure to parents across adolescence. Results also revealed relations between class membership and both predictors at age 12 and outcomes at age 18 that help us to identify groups of adolescents who might be at particular risk.

\section{Trajectories of Child Disclosure to Parents}

The largest group of adolescents found in the current study (82\%) followed a trajectory of disclosure similar to that found in other studies, with relatively high levels of disclosure in early adolescence, a gradual decrease across adolescence, and a slight increase from age 16-18. Thus, it is safe to say that the majority of teens follow the pattern that has been found in other studies (e.g., Keijsers \& Poulin, 2013), and that this pattern represents a healthy decline in disclosure as teens become more autonomous, with a slight rebound during late adolescence. However, two additional trajectories emerged in the current study, which have not been captured in past studies. First, almost $15 \%$ of the sample displayed a level of low disclosure to parents across adolescence, while a third and smaller group (5\%) started with high levels of disclosure but reported a relatively steep decline before a rebound from age 16 to 18 .

These findings are important because they demonstrate that meaningful variations in the patterns of disclosure across adoles-

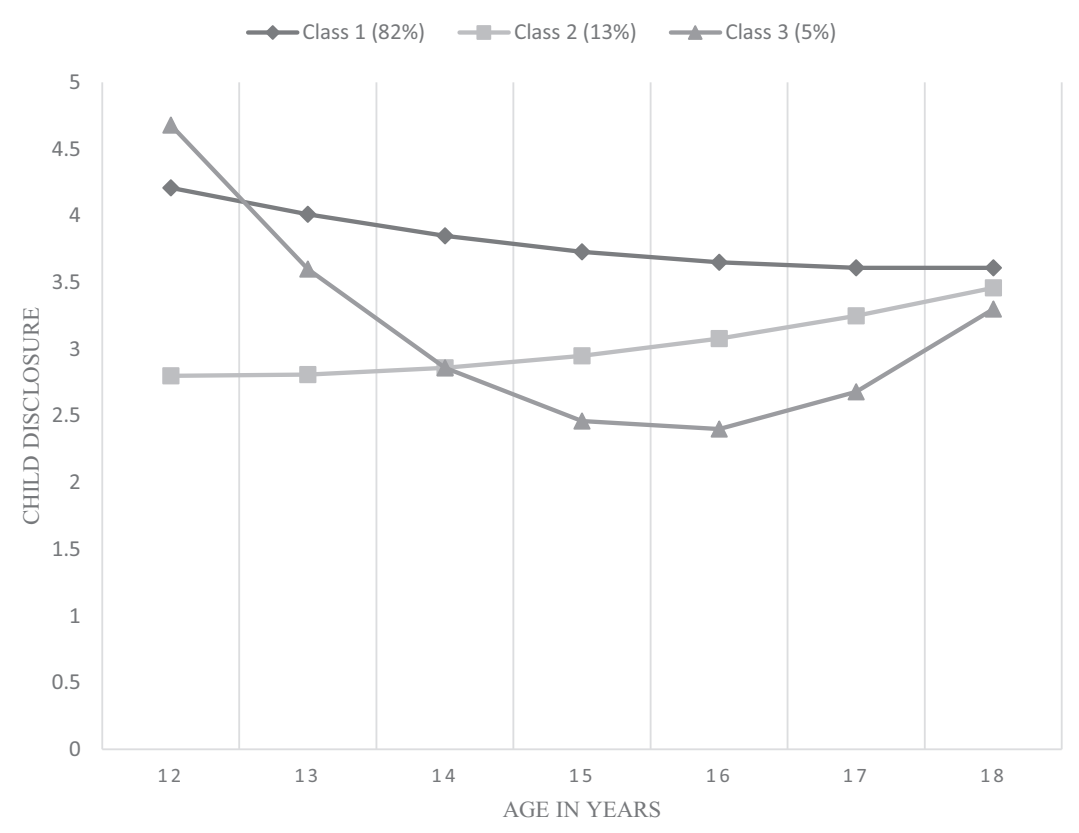

Figure 2. Growth mixture model of child disclosure. 
Table 3

Growth Parameters for Each Class

\begin{tabular}{cccc}
\hline Class \# (\% of sample) & Intercept b $(S E)$ & Linear slope b $(S E)$ & Quadratic slope b $(S E)$ \\
\hline $1(82 \%)$ & $4.21^{* * * * *}(.07)$ & $-.22^{* * * *}(.04)$ & $.02^{* *}(.01)$ \\
$2(13 \%)$ & $2.80^{* * * *}(.24)$ & $-.01(.15)$ & $.02(.02)$ \\
$3(5 \%)$ & $4.68^{* * * *}(.21)$ & $-1.25^{* * * *}(.15)$ & $.17^{* * * *}(.03)$ \\
\hline${ }^{* * *} p<.01 .^{* * *} p<.001$. & &
\end{tabular}

cence exist. The work showing general patterns of disclosure among adolescence is certainly important in showing us broad developmental trends in parent-child communication across adolescence. However, in looking at general trends, we miss the heterogeneity that exists among adolescents. It is especially important to identify those who might be at risk, and the current study suggests that this may include as many as $20 \%$ of adolescents. Future research should seek to replicate the current findings, as the relatively well-adjusted sample may be underestimating those adolescents who display low child disclosure as one aspect of what may be a larger constellation of risk behaviors. In addition, these results raise the question of why or how different patterns of disclosure are related to indices of adjustment and maladjustment during late adolescence. Parents and children continuously adjust different aspects of their relationship (e.g., intimacy, boundary) and adolescents may use disclosure or concealment strategies in order to manage their relationship with parents. For example, children may gradually decrease the amount of disclosure in order to gain more autonomy and privacy (Keijsers, Branje, Frijns, Finkenauer, \& Meeus, 2010; Laird et al., 2013), though these findings suggest that some adolescents resort to more extreme decreases or may have been concealing long before adolescence. These different patterns of adolescent disclosure may be influenced significantly by aspects of child or the parent-child relationship that were established during childhood, and may also influence young people's subsequent levels of well-being and adjustment.

Table 4

Logistic Regression Parameters Predicting Class Membership

\begin{tabular}{|c|c|c|}
\hline Comparison Category $=1$ & $\begin{array}{c}1 \text { Gradual decrease } \\
\text { b }(S E)\end{array}$ & $\begin{array}{c}2 \text { Low-stable } \\
\text { b }(S E)\end{array}$ \\
\hline \multicolumn{3}{|l|}{2 (Low-stable) } \\
\hline Male $^{\mathrm{a}}$ & $-.27(.46)$ & - \\
\hline Single parent ${ }^{\mathrm{b}}$ & $1.54(.51)$ & - \\
\hline Delinquency & $4.22(1.07)^{* * * *}$ & - \\
\hline Prosocial behavior & $-2.24(.88)^{* * *}$ & - \\
\hline Maternal warmth & $-2.29(.58)^{* * *}$ & \\
\hline \multicolumn{3}{|l|}{3 (Sharp decrease-increase) } \\
\hline Male $^{\mathrm{a}}$ & $1.27(1.04)$ & $1.54(.1 .17)$ \\
\hline Single parent ${ }^{\mathrm{b}}$ & $.76(.32)$ & $-.78(.36)$ \\
\hline Delinquency & $1.23(2.09)$ & $-2.99(2.02)$ \\
\hline Prosocial behavior & $.11(4.01)$ & $2.34(4.30)$ \\
\hline Maternal warmth & $1.06(2.03)$ & $3.35(2.06)^{\dagger}$ \\
\hline
\end{tabular}

\section{Predictors and Outcomes of Child Disclosure Trajectories}

Research on predictors of child disclosure shows that a number of variables influence the frequency of child disclosure, including some that are parent-driven (e.g., authoritative parenting; Darling, Cumsille, Caldwell, \& Dowdy, 2006), some that are child-driven (e.g., perceived obligations to disclose, delinquency; Smetana, Metzger, Gettman, \& Campione-Barr, 2006), and some that are family-level factors (e.g., shared decision making; Padilla-Walker et al., 2011). The current study adds to this body of research by suggesting that adolescents who had low levels of disclosure across adolescence had higher rates of delinquency and lower rates of prosocial behavior and maternal warmth at age 12 compared to the normative group that gradually declined and then levelled out during late adolescence. Given that prosocial behavior toward family and maternal warmth are both indicators of the quality of the parent-child relationship, this finding suggests that a small but significant group of adolescents may enter the teen years at risk of low disclosure (and other negative outcomes) because of a relatively poor relationship with parents in childhood.

Similar to findings regarding predictors, adolescents with the most risky outcomes at age 18, including the highest levels of delinquency and substance use, and the lowest levels of prosocial behavior, were adolescents in the low-stable disclosure group. These findings suggest that poor parent-child relationships compounded over time (and evidenced in part by lower levels of child disclosure) are meaningfully associated with behavioral outcomes during late adolescence. Interestingly, levels of maternal warmth were similarly moderate for all three groups by age 18 , suggesting that the parent-child relationship and its influence on child adjustment outcomes may change during the transition to adulthood. Given that levels of child disclosure also converged by age 18 , it is possible that other aspects of the parent-child relationship become more salient during late adolescence when expectations for routine disclosure might decrease overall. Indeed, some behaviors that are considered delinquent during adolescence (e.g., smoking and drinking alcohol) become legal or are perceived to be less negative by age 18 , and other routine disclosure behaviors (e.g., what is done in free time) seem less relevant to parents when children are living outside the parental home or are no longer in high school. Thus, it will be important to explore developmentally pertinent aspects of parent-child relationships that may characterize risk during the transition to adulthood, such as parental control and helicopter parenting (Schiffrin et al., 2014). Indeed, research has found that parental control of any form is ineffective during the transition to adulthood (Nelson et al., 2011), and so parental control attempts may more meaningfully distinguish between 
Table 5

Test of Mean Differences Across Outcome Variables as a Function of Class

\begin{tabular}{lcccc}
\hline Outcome Age 18 & $\begin{array}{c}\text { Class } 1 M(S E) \\
\text { Gradual decrease }\end{array}$ & $\begin{array}{c}\text { Class } 2 M(S E) \\
\text { Low-stable }\end{array}$ & $\begin{array}{c}\text { Class 3 } M(S E) \\
\text { Sharp decrease }\end{array}$ & Overall $\chi^{2}$ \\
\hline Delinquency & $.30(.02)_{\mathrm{a}}$ & $.66(.07)_{\mathrm{b}}$ & $.48(.10)_{\mathrm{b}}$ & $24.83^{* * * * *}$ \\
Substance use & $1.44(.09)_{\mathrm{a}}$ & $2.93(.22)_{\mathrm{b}}$ & $2.54(.39)_{\mathrm{b}}$ & $39.41^{* * * * *}$ \\
Depression & $1.64(.12)$ & $2.22(.27)$ & $2.52(.52)$ & 2.69 \\
Prosocial behavior & $4.25(.07)_{\mathrm{a}}$ & $3.78(.26)_{\mathrm{b}}$ & $3.33(.36)_{\mathrm{b}}$ & $11.19^{* * *}$ \\
Parental warmth & $3.78(.05)$ & $3.75(.13)$ & $4.20(.32)$ & 1.61 \\
\hline
\end{tabular}

Note. Means with differing subscripts are statistically different at $p<.05$.

*** $p<.01 .{ }^{* * * *} p<.001$.

those who are at risk and those who are not during the transition to adulthood.

Taken together, these are important findings in terms of intervention efforts, suggesting that helping parents to increase the quality of interactions during childhood and early adolescence might result in increased parental knowledge due to child disclosure across the teen years. This is especially important because these results suggest that consistently low levels of disclosure, while not impacting the parent-child relationship in the long run, may be an important indicator of risky behavior during late adolescence. Notably, this study is also one of the first to link low levels of disclosure not only to negative behavioral outcomes, but also to the lack of positive or prosocial outcomes (Laird \& Zeringue, in press), suggesting that the impact of parental disclosure and potentially parental knowledge are more far-reaching than previously explored.

Notably, there were few differences in predictors or outcomes when comparing the sharp decrease-increase group with the lowstable group, save a marginal finding suggesting higher initial levels of maternal warmth in the sharp decrease-increase group. This finding again highlights the importance of the parent-child relationship in determining initial levels of disclosure (e.g., Racz \& McMahon, 2011), but answers little else in regard to the sharp decrease-increase group, leading to a need to more carefully explore a potential group of teens who start by disclosing much to their parents but become considerably less disclosing over time compared to all other groups. One possible explanation for this steep decline is that it is a function of the fulfillment of adolescents' needs for autonomy, as research has found parental control to be associated with poor adjustment outcomes through youth feeling overcontrolled (Kakihara, Tilton-Weaver, Kerr, \& Stattin, 2010). It is possible that parents of the sharp decrease-increase group were both relatively warm and controlling (Nelson, PadillaWalker, \& Nielson, 2015). Whereas this did not impact disclosure in early adolescence, as the developmental need for autonomy increased with similar levels of control from parents, disclosure declined due to adolescents feeling that their parents had invaded privacy (Hawk, Hale, Raaijmakers, \& Meeus, 2008). Certainly future research is needed to more carefully explore this possibility and others. Whereas this appears to be a more extreme version of the largest class (gradual decline), the steep decline could also be attributed to child temperament or cognitive status.

It is also of note that depression at age 18 did not differ as a function of the trajectory of disclosure, which is inconsistent with some studies that have found disclosure to be negatively associated with depressive symptoms (Laird et al., 2013). The link between depression and disclosure may not be strong when child disclosure is measured as routine disclosure to parents about daily activities and whereabouts (Tilton-Weaver, Marshall, \& Darling, 2014), because such communication focuses on behaviors and not on internal states. Exploring how depression is related to adolescent self-disclosure (i.e., sharing more private and intimate information; Tilton-Weaver et al., 2014) to parents would be important since adolescents with depressive symptoms may be less willing to share their personal feelings and thoughts with their parents than their nondepressed peers (Kahn \& Garrison, 2009).

\section{Limitations and Conclusions}

Although this study contributes meaningfully to the existing literature on child disclosure, it is not without limitations. Most importantly, the current study is relatively homogeneous in terms of ethnicity and socioeconomic status. Given that this is a study seeking to explore heterogeneity, we may not have captured all existing trajectories of disclosure given our sample and future research should continue to explore these questions with more diverse samples. In addition, all variables in the current study were child-reported. This seems appropriate when assessing child disclosure, but results may have been influenced by shared method variance and future studies should consider both parent and child perceptions of disclosure and child outcomes. Indeed, past research has found parent- and child-reports to differ meaningfully in both mean levels and in patterns of associations between child disclosure and other parenting behaviors and child outcomes (e.g., Kerr et al., 2010). Also, the current study only considered disclosure, but future research should also consider the heterogeneity of child secrecy, parental solicitation, parental control, and parental knowledge, as it would be interesting to determine whether trajectories were similar or different in these dynamics of the parentchild relationship over time, and might provide a more holistic picture of this process.

Despite these limitations, this study makes several important contributions to our understanding of the patterns of child disclosure during adolescence. In addition to the normative decline in the frequency of child disclosure, this study captures two additional trajectories that highlight a sizable minority of adolescents who disclose relatively little to their parents over time. Furthermore, this study suggests that the quality of the parent-child relationship and the child's own level of delinquency during early adolescence are most consistently associated with different trajectories over time. Similarly, those who disclose little to their parents are considerably less well-adjusted in late adolescence. 
These findings have important implications for potential intervention efforts aimed at increasing child disclosure to parents in at-risk groups of adolescents.

\section{References}

Barber, B. K., Stolz, H. E., \& Olsen, J. A. (2005). Parental support, psychological control, and behavioral control: Assessing relevance across time, culture, and method. Monographs of the Society for Research in Child Development, 70, 1-137. http://dx.doi.org/10.1111/j.1540-5834.2005 .00365.x

Bumpus, M. F., Crouter, A. C., \& McHale, S. M. (2001). Parental autonomy granting during adolescence: Exploring gender differences in context. Developmental Psychology, 37, 163-173. http://dx.doi.org/10.1037/0012-1649 .37.2.163

Carlson, M. J., \& Berger, L. M. (2013). What kids get from parents: Packages of parental involvement across complex family forms. Social Service Review, 87, 213-249. http://dx.doi.org/10.1086/671015

Celeux, G., \& Soromenho, G. (1996). An entropy criterion for assessing the number of clusters in a mixture model. Journal of Classification, 13, 195-212. http://dx.doi.org/10.1007/BF01246098

Crouter, A. C., \& Head, M. R. (2002). Parental monitoring and knowledge of children. In M. H. Bornstein (Ed.), Handbook of parenting, Vol. 3: Being and becoming a parent (2nd ed., pp. 461-483). Mahwah, NJ: Erlbaum.

Cumsille, P., Darling, N., \& Martínez, M. L. (2010). Shading the truth: The patterning of adolescents' decisions to avoid issues, disclose, or lie to parents. Journal of Adolescence, 33, 285-296. http://dx.doi.org/10.1016/ j.adolescence.2009.10.008

Darling, N., Cumsille, P., Caldwell, L. L., \& Dowdy, B. (2006). Predictors of adolescents' disclosure to parents and perceived parental knowledge: Between- and within-person differences. Journal of Youth and Adolescence, 35, 659-670. http://dx.doi.org/10.1007/s10964-006-9058-1

Garthe, R. C., Sullivan, T., \& Kliewer, W. (2015). Longitudinal relations between adolescent and parental behaviors, parental knowledge, and internalizing behaviors among urban adolescents. Journal of Youth and Adolescence, 44, 819-832. http://dx.doi.org/10.1007/s10964-014-0112-0

Hawk, S. T., Hale, W. W., III, Raaijmakers, Q. A., \& Meeus, W. (2008). Adolescents' perceptions of privacy invasion in reaction to parental solicitation and control. The Journal of Early Adolescence, 28, 583-608. http://dx.doi.org/10.1177/0272431608317611

Kahn, J. H., \& Garrison, A. M. (2009). Emotional self-disclosure and emotional avoidance: Relations with symptoms of depression and anxiety. Journal of Counseling Psychology, 56, 573-584. http://dx.doi.org/ 10.1037/a0016574

Kakihara, F., Tilton-Weaver, L., Kerr, M., \& Stattin, H. (2010). The relationship of parental control to youth adjustment: Do youths' feelings about their parents play a role? Journal of Youth and Adolescence, 39, 1442-1456. http://dx.doi.org/10.1007/s10964-009-9479-8

Keijsers, L., Branje, S. J., Frijns, T., Finkenauer, C., \& Meeus, W. (2010). Gender differences in keeping secrets from parents in adolescence. Developmental Psychology, 46, 293-298. http://dx.doi.org/10.1037/a0018115

Keijsers, L., Branje, S. J., VanderValk, I. E., \& Meeus, W. (2010). Reciprocal effects between parental solicitation, parental control, adolescent disclosure, and adolescent delinquency. Journal of Research on Adolescence, 20, 88-113. http://dx.doi.org/10.1111/j.1532-7795.2009.00631.x

Keijsers, L., Frijns, T., Branje, S. J., \& Meeus, W. (2009). Developmental links of adolescent disclosure, parental solicitation, and control with delinquency: Moderation by parental support. Developmental Psychology, 45, 1314-1327. http://dx.doi.org/10.1037/a0016693

Keijsers, L., \& Poulin, F. (2013). Developmental changes in parent-child communication throughout adolescence. Developmental Psychology, 49, 2301-2308. http://dx.doi.org/10.1037/a0032217
Kerr, M., \& Stattin, H. (2000). What parents know, how they know it, and several forms of adolescent adjustment: Further support for a reinterpretation of monitoring. Developmental Psychology, 36, 366-380. http://dx.doi.org/10.1037/0012-1649.36.3.366

Kerr, M., Stattin, H., \& Burk, W. J. (2010). A reinterpretation of parental monitoring in longitudinal perspective. Journal of Research on Adolescence, 20, 39-64. http://dx.doi.org/10.1111/j.1532-7795.2009.00623.x

Laird, R. D., \& Marrero, M. D. (2010). Information management and behavior problems: Is concealing misbehavior necessarily a sign of trouble? Journal of Adolescence, 33, 297-308. http://dx.doi.org/10.1016/j.adolescence.2009 .05 .018

Laird, R. D., Marrero, M. D., Melching, J. A., \& Kuhn, E. S. (2013). Information management strategies in early adolescence: Developmental change in use and transactional associations with psychological adjustment. Developmental Psychology, 49, 928-937. http://dx.doi.org/10.1037/ a0028845

Laird, R. D., \& Zeringue, M. M. (in press). Parental knowledge and child disclosure as they relate to prosocial and antisocial behaviors. In D. Laible, G. Carlo, \& L. M. Padilla-Walker (Eds.), Oxford handbook of parenting and moral development. New York, NY: Oxford University Press.

Laursen, B. P., \& Hoff, E. (2006). Person-centered and variable-centered approaches to longitudinal data. Merrill-Palmer Quarterly, 52, 377-389. http://dx.doi.org/10.1353/mpq.2006.0029

Marshall, S. K., Tilton-Weaver, L. C., \& Bosdet, L. (2005). Information management: Considering adolescents' regulation of parental knowledge. Journal of Adolescence, 28, 633-647. http://dx.doi.org/10.1016/j .adolescence.2005.08.008

McLanahan, S., Tach, L., \& Schneider, D. (2013). The causal effects of father absence. Annual Review of Sociology, 39, 399-427. http://dx.doi .org/10.1146/annurev-soc-071312-145704

Moberg, D. P., \& Hahn, L. (1991). The Adolescent Drug Involvement Scale. Journal of Adolescent Chemical Dependency, 2, 75-88.

Muthén, L. K., \& Muthén, B. O. (2010). Mplus user's guide (6th ed). Los Angeles, CA: Author.

Nelson, L. J., Padilla-Walker, L. M., Christensen, K. J., Evans, C. A., \& Carroll, J. S. (2011). Parenting in emerging adulthood: An examination of parenting clusters and correlates. Journal of Youth and Adolescence, 40, 730-743. http://dx.doi.org/10.1007/s10964-010-9584-8

Nelson, L. J., Padilla-Walker, L. M., \& Nielson, M. G. (2015). Is hovering smothering or loving? An examination of parental warmth as a moderator of relations between helicopter parenting and emerging adults' indices of adjustment. Emerging Adulthood, 3, 282-285. http://dx.doi .org/10.1177/2167696815576458

Padilla-Walker, L. M., Harper, J. M., \& Bean, R. A. (2011). Pathways to parental knowledge: The role of family process and family structure. The Journal of Early Adolescence, 31, 604-627. http://dx.doi.org/10.1177/ 0272431610366246

Peterson, C., \& Seligman, M. E. P. (2004). Character strengths and virtues: A handbook and classification. Washington, DC: American Psychological Association/New York, NY: Oxford University Press.

Racz, S. J., \& McMahon, R. J. (2011). The relationship between parental knowledge and monitoring and child and adolescent conduct problems: A 10-year update. Clinical Child and Family Psychology Review, 14, 377-398. http://dx.doi.org/10.1007/s10567-011-0099-y

Robinson, C. C., Mandleco, B., Olsen, S. F., \& Hart, C. H. (2001). The Parenting Styles and Dimensions Questionnaire (PSDQ). In B. F. Perlmutter, J. Touliatos, \& G. W. Holden (Eds.), Handbook of family measurement techniques, Vol. 3: Instruments \& index (pp. 319-321). Thousand Oaks, CA: Sage.

Salari, R., \& Thorell, L. B. (2015). Parental monitoring in late adolescence: Relations to ADHD symptoms and longitudinal predictors. Journal of Adolescence, 40, 24-33. http://dx.doi.org/10.1016/j.adolescence.2015 .01 .002 
Schiffrin, H. H., Liss, M., Miles-McLean, H., Geary, K. A., Erchull, M. J., \& Tashner, T. (2014). Helping or hovering? The effects of helicopter parenting on college students' well-being. Journal of Child and Family Studies, 23, 548-557. http://dx.doi.org/10.1007/s10826-013-9716-3

Smetana, J. G., Metzger, A., Gettman, D. C., \& Campione-Barr, N. (2006). Disclosure and secrecy in adolescent-parent relationships. Child Development, 77, 201-217. http://dx.doi.org/10.1111/j.14678624.2006.00865.x

Smetana, J. G., Villalobos, M., Tasopoulos-Chan, M., Gettman, D. C., \& Campione-Barr, N. (2009). Early and middle adolescents' disclosure to parents about activities in different domains. Journal of Adolescence, 32, 693-713. http://dx.doi.org/10.1016/j.adolescence.2008.06.010

Soenens, B., Vansteenkiste, M., Luyckx, K., \& Goossens, L. (2006). Parenting and adolescent problem behavior: An integrated model with adolescent self-disclosure and perceived parental knowledge as intervening variables. Developmental Psychology, 42, 305-318. http://dx.doi .org/10.1037/0012-1649.42.2.305

Stattin, H., \& Kerr, M. (2000). Parental monitoring: A reinterpretation. Child Development, 71, 1072-1085. http://dx.doi.org/10.1111/1467-8624.00210

Tilton-Weaver, L. (2014). Adolescents' information management: Comparing ideas about why adolescents disclose to or keep secrets from their parents. Journal of Youth and Adolescence, 43, 803-813. http://dx.doi .org/10.1007/s10964-013-0008-4
Tilton-Weaver, L., Kerr, M., Pakalniskeine, V., Tokic, A., Salihovic, S., \& Stattin, H. (2010). Open up or close down: How do parental reactions affect youth information management? Journal of Adolescence, 33, 333-346. http://dx.doi.org/10.1016/j.adolescence.2009.07.011

Tilton-Weaver, L. C., Marshall, S. K., \& Darling, N. (2014). What's in a name? Distinguishing between routine disclosure and self-disclosure. Journal of Research on Adolescence, 24, 551-563. http://dx.doi.org/10 .1111/jora. 12090

Tofighi, D., \& Enders, C. K. (2008). Identifying the correct number of classes in growth mixture models. In G. R. Hancock \& K. M. Samuelsen (Eds.), Advances in latent variable mixture models (pp. 317-341). Charlotte, NC: Information Age Publishing.

Willoughby, T., \& Hamza, C. A. (2011). A longitudinal examination of the bidirectional associations among perceived parenting behaviors, adolescent disclosure and problem behavior across the high school years. Journal of Youth and Adolescence, 40, 463-478. http://dx.doi.org/10 .1007/s10964-010-9567-9

Received July 10, 2017

Revision received September 12, 2017

Accepted September 14, 2017 